\title{
Reflexões sobre formação de professores, linguagem e tecnologias
}

Rodrigo Esteves de Lima-Lopes

Professor da Universidade Estadual de Campinas (Unicamp). Doutor em Linguística Aplicada pela mesma instituição. Lider do Grupo MiDiTeS.

E-mail: rll307@unicamp.br

Marco Túlio Câmara

Doutorando em Linguística Aplicada na Unicamp, bolsista CNPq, mestre em Estudos de Linguagens pelo Cefet-MG e jornalista pela UFV. Integrante do grupo MiDiTeS e CRIAB.

E-mail: marcotuliocamara@gmail.com

Maria Luiza Tápias Oliveira

Graduada em Letras pela Unicamp. Desenvolve pesquisa nas áreas de Linguagem e Tecnologia, Análise de Obras em Arte Sequencial e Português como LE/LA.

E-mail:marialu001@gmail.com

Resumo: Este artigo tem por objetivo discutir os processos de transformação que uma disciplina do curso de letras na Unicamp sofreu por conta do distanciamento social e do Ensino Emergencial Remoto, ambos impostos pela pandemia de Covid-19 em 2020. A disciplina de Linguagem e Tecnologias já possuía um importante componente relacionado à comunicação e sua importância no ensino. Entretanto, a nova situação levou ao fortalecimento desses laços, dada a premente necessidade dos alunos de interagir no novo contexto que se colocou. Por meio da discussão do curso, dos objetivos e das modificações feitas para atender esse contexto, refletiremos sobre os resultados do curso e os processos metodológicos utilizados.

Palavras-chave: educomunicação; linguagem e tecnologias; ensino emergencial remoto; ensino e comunicação; formação de professores.
Abstract: This article aims to discuss the changes that a module in the undergraduate program in Letras at Unicamp underwent due to social distancing and Remote Emergency Classes, both imposed by the world's pandemic in 2020. The module named "Language and Technologies" already had an important component related to communication and its importance in teaching. However, the new situation led to the strengthening of these themes, given the pressing need for students to interact in the new context that had arisen. By discussing the course, its objectives and the changes made to adapt it to this new context, we reflect upon the course results and the methodological processes.

Keywords: educommunication; language and technologies; distance education; education and communication; teacher education. 


\section{INTRODUÇÃO}

Este relato visa discutir os processos de transformação que a disciplina Linguagem e Tecnologias passou a ter devido ao distanciamento social e, consequentemente, pelo Ensino Emergencial Remoto imposto a partir de 13 março de 2020 na Unicamp pela Resolução GR 24/2020, de 16/03/2020. Tal disciplina é oferecida em caráter obrigatório na graduação em Letras da Universidade Estadual de Campinas e busca debater a relação entre a comunicação, tecnologia e ensino de línguas. Planejada inicialmente para ser oferecida na modalidade presencial, o objetivo dela é compreender e valorizar a interface entre a educação e a comunicação, enquanto saberes e práticas convergentes e complementares. Sendo assim, a proposta do curso foi reformulada, tendo como base as temáticas da educação e da comunicação. Nesse cenário, é importante considerar a Educomunicação e a Educação para os Meios como práticas e reflexões das relações estabelecidas em um espaço escolar, além de se firmá-las enquanto recursos pedagógicos que aliam os debates às disputas observadas no campo midiático.

Por se tratar de uma disciplina obrigatória, a Unicamp permite a presença de até dois monitores, sendo um bolsista PED-B, um aluno de pós-graduação em nível de doutorado e responsável por $20 \%$ das atividades pedagógicas de regência, e um bolsista $\mathrm{PAD}$, estudante em nível de graduação que já tenha realizado a disciplina com excepcional desempenho acadêmico. É importante ressaltar que os bolsistas foram essenciais no processo de transformação, de forma a construir o novo caminho a ser trilhado pela mudança repentina que o contexto social da pandemia gerou.

Nesse sentido, o presente texto está organizado em três outras seções. Na seção 2, discutiremos a disciplina a partir da epistemologia teórico-prática. Seguiremos para uma reflexão sobre as transformações por ocasião do Ensino Remoto Emergencial, incluindo algumas produções realizadas pelos alunos para, então, partirmos para as considerações finais.

\section{EDUCAÇÃO E COMUNICAÇÃO EM DEBATE: CONTEXTO GERAL E OBJETIVO DA DISCIPLINA}

No processo da formação dos professores de línguas, raras são as discussões sobre o papel dos processos de comunicação tecnologicamente mediados. Uma consequência direta disso é o ensino centrando ora em questões estruturais da linguagem, ora em produções que não necessariamente observam o papel social que os diferentes meios e suportes possuem em nossa sociedade, o que faz a discussão tecnológico-midiática chegar a um patamar de fascínio quase divino ${ }^{1}$. Levando em consideração a importância de uma reflexão mais aprofundada sobre os meios na formação do futuro professor, propor tais reflexões para os futuros educadores se torna essencial. Nesse sentido, concordamos com Assis e Farbiarz ${ }^{2}$ no que tange à formação do educador, que deve primar pela liberdade, 
com exemplos práticos e críticos acerca do uso das mídias e da comunicação no dia a dia dos estudantes. Mais do que encarar a mídia enquanto poder absoluto em seu papel impositivo, devemos levar em consideração, também, a receptividade dos alunos a esses produtos, compreendendo o papel das linguagens nesse processo de (re)significação das mensagens ali veiculadas ${ }^{3}$.

Dessa forma, é fundamental levar em conta a diversidade de formatos e linguagens para que o consumo e produção midiáticos ocorram e sejam incentivados nos espaços escolares. Assim, julgamos salutar que essas contextualizações sejam atualizadas não só com o que esses estudantes, imersos no ambiente digital, consomem, mas compreender como se dão esses usos, de forma a considerá-los um espaço para o aprendizado e cidadania ${ }^{4}$. Tais práticas de ensino, perpassadas pelos usos de mídias e tecnologias de comunicação e informação, não são novas. No entanto, tendo em vista o cenário atual em que tal relação passou a ser não só incentivada e presente, mas também imposta e cotidiana, ancoramos nosso debate de se tornar "viável executar os trânsitos discursivos multidimensionais” (CITELLI, 2019, p. 19).

Nesse aspecto, ressaltamos a relevância de estudos acerca da multimodalidade não só relacionada aos recursos e aparatos midiáticos, como em sites e vídeos $^{5}$, mas também aplicadas ao ensino, presencial ou à distância ${ }^{6}$. Acreditamos que, para que todo esse debate sobre Educomunicação, mídias, tecnologias e educação seja aplicado de modo mais eficaz, os discursos devem ser pensados, usados e atribuídos de modo ampliado, considerando seu caráter multimodal, fazendo uso dos recursos que tais aparatos e tecnologias permitem.

Pensando em uma possível solução para esses problemas, abordamos a relevância da educação para os meios para além dos recursos tecnológicos disponíveis e utilizados em suas implementações e atuações. Tal campo de estudo considera as múltiplas possíveis relações que podem ser estabelecidas entre os sujeitos e as mídias/meios que eles consomem, produzem e interagem, independente da inovação tecnológica que o aparato carrega.

No contexto heterogêneo que a escola se apresenta, torna-se essencial que os jovens possam participar mais ativamente das interações com as mídias, passando a ser produtores de conteúdos, além dos consumos habituais ${ }^{7}$. Vislumbrar essa possibilidade é fundamental para uma educação mais atual e contextualizada, uma vez que considera as novas relações que se estabelecem entre esses sujeitos e as mídias com as quais interagem em suas rotinas.

Assim, refletimos sobre a essencial relação estabelecida entre a linguagem e as tecnologias, com especial ênfase nas transformações decorrentes dos constantes processos de tecnologização da sociedade e seus impactos no sujeito contemporâneo, assim como na concepção de conhecimento ${ }^{8}$. A perspectiva adotada é social, tendo o ensino de línguas como norte. Desse modo, busca-se refletir sobre os ecossistemas comunicativos ${ }^{9}$ da atualidade e seu papel na escola, partindo de como nossa sociedade da informação e seu impacto na produção textual e ensino de línguas.

A disciplina poderia ser dividida em três módulos. No primeiro, busca-se uma definição de tecnologia que fuja do senso comum, salientando o caráter
2. ASSIS, Leandro Marlon Barbosa; FARBIARZ, Alexandre. Conectar ou desconectar. Comunicação \& Educação, São Paulo, v. 23 n. 2, p. 21-33, 2018.

3. CITELLI, Adilson; SOA RES, Ismar de Oliveira: LOPES, Maria Immacolata Vassalo de. Educomunicação: Referências para uma construção metodológica, Comunicação \& Educação São Paulo, v. 24, n. 2, p. 1225,2019

4. GABARDO, Maristella. Derrubando os muros: por que a escola brasileira deveria conhecer os usos da mídia feitos pelos adolescentes?. In: LIMA-LOPES Rodrigo Esteves de; GABARDO, Maristella (org.). Horizontes em tecnologia, ensino e sociedade: diálogos interdisciplinares em linguística aplicada. Curitiba: Editora do IFPR, 2021. p. 35-54.

5. MARTINEC, Radan. Nascent and mature uses of a semiotic system: the case of image-text relations. Visual Communication, Thousand Oaks, v. 12, n. 2, p. 147-172 2013; O'HALLORAN, Kay L. Visual semiosis in film. In: O'HALLORAN, Kay L. (org.). Multimodal discourse analysis: systemic-functional perspectives. London: Continuum, 2004. p. 118 130.

6. LIMA-LOPES, Rodrigo Esteves de. Mídia e comunicação: reflexões e possibilidades para o ensino e aprendizagem de línguas. In: CONGRESSO IBERCOM 2017: COMUNICAÇÃO, DIVERSIDADE ETOLERÂN CIA, 15., 2018, São Paulo. Anais [...]. São Paulo: ECA-USP, 2018. p. 1463-1480.

7. BUCKINGHAM, David. Media education: literacy, learning, and contemporary culture. Cambridge: Polity Press, 2003.

8. LÉVY, Pierre. Os três tempos do espírito: a oralidade primária, a escrita e a informática. In: LÉVY, Pierre. As tecnologias da inteligência. São Paulo: Editora 34, 1997.

9. SCOLARI, Carlos Alberto. Ecología de los medios entornos, evoluciones e interpretaciones, Barcelona: Gedisa, 2015 
10. FLUSSER, Vilém. Língua e realidade. São Paulo: Annablume, 2007.

11. FLUSSER, Vilém. O mundo codificado. São Paulo: Cosac Naif, 2007.

12. CHOMSKY, Noam. Aspects of the Theory of Syntax, Cambridge/Mass: M.I.T. Press, 1969; LYONS, J. Semantics: Volume 1, Cambridge: Cambridge University Press, 1977.

13. HALLIDAY, Michael. Language as social semiotic: the social interpretation of language and meaning London: University Park Press, 1978; KRESS, Gunther. Against arbitrariness: the social production of the sign as a foundational issue in critical discourse analysis. Discourse \& Society, Thousand Oaks, v. 4, n. 2, p. 169-191, 1993.

14. LIMA-LOPES, Rodrigo Esteves de; CÂMARA, Marco Túlio. Arco-íris na cruz: a multimodalidade no midiativismo em vídeos no YouTube. Policromias, Rio de Janeiro, v. 4, n. 2, p. 78102, 2019

15. LIMA-LOPES, Rodrigo Esteves de. Apontamentos sobre mídias digitais: qual caminho para o Gênero 2.0?. In: LIMA-LOPES, Rodrigo Esteves de; BUZATO, Marcelo El Khouri (org.). Gênero reloading. Campinas: Pontes, 2018. p. 15-41.

16. BUZATO, Marcelo El Khouri. Data storytelling e a datificação de tudo: um gênero bastardo de mãe narrativa e pai banco de dados. In: LIMA-LOPES, Rodrigo Esteves de; BUZATO, Marcelo El Khouri (org.). Gênero reloading. Campinas: Pontes, 2018. p. 95-124.

17. SOARES, Magda. Novas práticas de leitura e escrita: letramento na cibercultura. Educação \& Sociedade, v. 23, n. 81, p. 143-160, 2002.

18. BUCKINGHAM, David. Precisamos realmente de educação para os meios? Comunicação \& Educação, São Paulo, v. 17, n. 2, p. 4160, 2012. de construção social e seu papel na construção da realidade humana ${ }^{10}$. Assim, procura-se refletir sobre as diferentes linguagens como construtos tecnológicos, uma das diversas máquinas de significar ${ }^{11}$, ao passo que a relação entre ela e as demais tecnologias se dá como parte de um ecossistema comunicativo.

Um dos resultados dessa reflexão é desnaturalização de alguns conceitos historicamente construídos na formação do professor de línguas, como o enfoque biológico da aquisição da linguagem ${ }^{12}$. Desse momento, esperava-se levar o aluno a refletir criticamente sobre o papel da tecnologia nas relações da linguagem, ao ponto de percebê-la como um processo tecnológico de mediação. Consequentemente, a tecnologia passa a ser um importante processo de construção da realidade, com significados motivados pelos diversos contextos sociais. Nesse momento, a ponte com as ciências da linguagem e os processos tecnológicos se dá graças a uma abordagem sociossemiótica, que busca analisar a linguagem dentro de seu contexto de produção ${ }^{13}$.

Segue-se, então, para a relação linguagem-meio-suporte, por vezes apagada nos contextos de formação do professor de letras. Busca-se compreender como os diferentes meios podem ser um elemento condicionador das escolhas linguísticas, problematizando-se sobre a questão do suporte e dos modos de linguagem ${ }^{14}$. Tal reflexão serve como fundo para uma percepção menos ingênua dos processos de transformação que a sociedade e a produção do conhecimento sofrem a partir da chamada revolução digital, não encarando-a como algo neutro, espontâneo, ou mesmo resultado de um processo de evolução natural.

A segunda parte da disciplina se relacionava à reflexão sobre processos tecnológicos e teorias sociais e pós-humanistas. Os processos de variação textual ${ }^{15}$ gerados pela natural instabilidade da internet e a datificação da sociedade ${ }^{16}$ causam um importante impacto, não apenas pelo fato de os alunos terem seu primeiro contato com tais temáticas, como também pela eminente percepção de que ela parece refletir sua realidade nas interações cotidianas online. Apesar da profundidade dos temas, eles estão presentes no planejamento inicial com o objetivo de se refletir sobre os diferentes algoritmos relacionados às nossas experiências online, propiciando a reflexão sobre essa temática em produções textuais.

A terceira parte está centrada em reflexões sobre literacias. Inicialmente, trazemos de um campo comum aos alunos, a partir da reflexão sobre letramento digital ${ }^{17}$. Parte-se, então, para outras abordagens, em especial a Educação para os Meios $^{18}$, Educomunicação ${ }^{19}$ e Transliteracias $^{20}$. A primeira abordagem tem por objetivo conscientizar o aluno das possíveis falácias de uma retórica educacional centrada, exclusivamente, nas plataformas digitais. O trabalho de Buckingham $^{21}$ ressalta as possibilidades trazidas pela inserção da mídia em sala de aula, tendo como ênfase especial não apenas os processos de recepção, mas também de produção, baseadas em experiências midiáticas online e offline. Já as reflexões no âmbito da Educomunicação têm como objetivo compreender o conceito de educação como ato comunicativo ${ }^{22}$, na construção de um arcabouço crítico para a relação intrínseca entre elas. 


\section{ADAPTAÇÕES REALIZADAS}

\subsection{Adaptações de conteúdo}

O isolamento social levou a diversas modificações nas temáticas tratadas na disciplina. Durante uma reunião na segunda semana de isolamento (ou quarta semana de aulas), observamos que os alunos iniciaram uma série de questionamentos sobre como as TIC poderiam ser integradas de forma a possibilitar o aprendizado em contexto de exceção. Além disso, a avalanche de dados referentes à pandemia mundial levou a percepção de que não havia uma discussão aprofundada nas disciplinas do curso sobre a temática da desinformação (fake news). Acreditamos que muitos desses questionamentos vieram do fato que diversos de nossos alunos já atuam como professores, passando por situações de continuidade de seu curso muito próximas a nossa. Sensíveis a essas necessidades, decidimos dar um novo formato ao curso, cancelando as leituras previstas e reformulando cronograma inicial da disciplina.

Entre as novas temáticas estavam as práticas contemporâneas e literacias digitais críticas, com especial ênfase nos Recursos Educacionais Abertos (REA) ${ }^{23}$. Buscamos, aqui, refletir sobre como os REAs podem ser utilizados de forma a oferecer material voltado para as necessidades contextualizadas de alunos e professores. Partiu-se então para reflexão sobre processos de mídia e educação, focando no papel da mídia na formação do jovem e na aprendizagem pela vida (life long learning) e na atenção aos impactos causados pela constante informatização da sociedade ${ }^{24}$.

Em seguida, buscamos refletir sobre as Transliteracias e o seu papel decisivo na construção crítica pela navegação em diferentes suportes midiáticos e informacionais. Para a última parte do curso, focamos nas diferentes práticas de Educomunicação e Educação para os Meios, enfatizando nos relatos de experiências. A desinformação foi tema de uma unidade específica ${ }^{25}$, objetivando discutir questões referentes a seu impacto na vida cotidiana dos alunos, assim como na compreensão da sociedade.

\subsection{Adaptações de caráter pedagógico}

Quando realizada de maneira tradicional, offline, a disciplina Linguagem $e$ Tecnologias é ministrada em forma de debate com intensa participação dos alunos. A sala é organizada em círculo e é solicitado aos discentes que dividam suas opiniões, dúvidas e impressões sobre o material lido. Como esta disciplina é ministrada para o $5^{\circ}$ semestre, parte significativa dos alunos já atua no magistério de cursos pré-vestibular, escolas particulares ou cursinhos comunitários na grande região de Campinas. Tal realidade faz com que haja uma intensa participação dos alunos no que tange à possível adaptação e transferência dos temas discutidos para sua realidade profissional. Metade da carga horária da disciplina (15 horas/aula) é cumprida com discussões de produtos midiáticos ou laboratórios de aplicação dos conteúdos teóricos estudados.
19. CITELLI, Adilson. Comunicação e educação: a linguagem em movimento. São Paulo: Editora Senac, 1999.

20. FRAU-MEIGS, Divina. Transletramento: operar a transição digital e o domínio das culturas da informação. Comunicação \& Educação, São Paulo, v. 19, n. 2, p. 61-73, 2014.

21. BUCKINGHAM, David. A evolução da educação midiática no Reino Unido: algumas lições da história. Comunicação \& Educação São Paulo, v. 21, n. 1, p. 73 84, 2016.

22. FREIRE, Paulo. Extensão ou comunicação?. São Paulo: Paz \& Terra, 2006.

23. AMIEL, Tel. Educação aberta: configurando ambientes, práticas e recursos educacionais. In: SANTANA, Bianca; PRETTO, Carolina; PRETTO, Nelson De Luca (org.). Recursos educacionais abertos: práticas colaborativas políticas públicas. Salvador: Edufba, 2012.

24. LASSALVIA, Catia Silene Camara. Aprendizagem ao longo da vida: entre a metonímia neoliberal e as trajetórias. In: LIMA-LOPES, Rodrigo Esteves de; GABARDO, Maristella (org.). Horizontes em tecnologia, ensino e sociedade: diálogos interdisciplinares em linguística aplicada. Curitiba: Editora do IFPR, [2021?]. No prelo.

25. COSTA, Maria Cristina Castilho; ROMANINI, Vinícius. A educomunicação na batalha contra as fake news. Comunicação \& Educação São Paulo, v. 24, n. 2, p. 66 77, 2019. 
26. VALENTE, José Armando. Blended learning e as mudanças no ensino superior: a proposta da sala de aula invertida. Educar em Revista, Curitiba, n. spe4, p. 79-97, 2014

27. MORAN, José. Mudando a educação com metodologias ativas. In: SOUZA, Carlos Alberto; MORALES, Ofelia Elisa Torres (org.). Convergências midiáticas, educação e cidadania: aproximações jovens. Ponta Grossa: [S. n.], 2015. p. 1533
Deve-se considerar que nem todos os alunos possuíam acesso constante à internet. De maneira geral, um dos grandes problemas apontados pela direção da Universidade foi a impossibilidade da maioria do corpo discente em frequentar aulas síncronas, razão pela qual optou-se por uma abordagem na qual os materiais ficassem disponibilizados de forma assíncrona e na qual os alunos entregavam suas contribuições. Optamos, assim, por um modelo de sala de aula invertida ${ }^{26}$ com eventual participação de professores e ativistas midiáticos externos. A escolha por esse modelo esteve apoiada na necessidade de tentar trazer para a experiência remota a mesma possibilidade de interação e livre discussão oferecida na modalidade presencial, buscando, por meio de metodologias ativas, engajar o aluno no processo de construção do conhecimento ${ }^{27} \mathrm{e}$ da experiência midiática que ela representa.

Após a reformulação do cronograma, solicitava-se aos alunos a leitura de textos relacionados aos novos temas, a fim de que produzissem as resenhas com liberdade para se organizarem em grupos com quaisquer números de integrantes, sendo que o formato de entrega da resenha poderia ser aquele que o grupo escolhesse. A ideia por trás de tal liberdade era de responsabilizar os alunos pela seleção do gênero, formato ou suporte que melhor traduzisse suas ideias e o fato do professor e o monitor de pós-graduação da disciplina serem comunicólogos tornou possível discutir configurações diferentes daquelas que os alunos estavam habituados, quando isso se fez necessário.

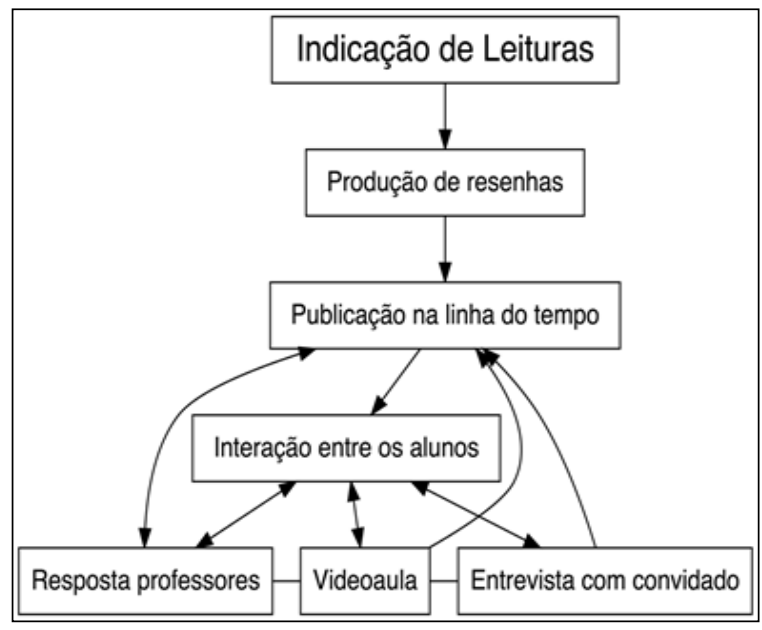

Figura 1: Fluxograma de trabalho no curso

A Figura 1 mostra um resumo de como o fluxo pedagógico da sala de aula invertida e sua aplicação no contexto de nossa disciplina.

Um ponto a ser levado em conta é o fato de que as produções eram publicadas na linha do tempo da plataforma em que o curso foi realizado, tornando-se públicas para todos os participantes da disciplina, sendo possível ler, ouvir e comentar os trabalhos de todos os colegas. O professor e os monitores do curso também interagiam constantemente, ora incentivando a produção de formatos que escapassem ao tradicional, ora comentando questões específicas do trabalho divulgado. 
Na sexta-feira de cada semana, o professor e os dois monitores do curso gravavam uma videoaula de 60 minutos comentando os trabalhos de forma anônima. Os comentários versavam sobre as questões teórico-práticas trazidas pela resenha, além da adequação ao formato e gênero escolhidos. A videoaula era, então, publicamente disponibilizada de forma que os discentes pudessem não apenas assisti-la, mas também comentá-la. Tais comentários eram respondidos tanto pelo professor e pelos monitores como também por outros alunos.

Durante o curso, foram realizadas entrevistas com dois convidados externos em momentos chave do curso, o educomunicador Ednan Kevin de Faria e a professora Maristella Gabardo (IFPR). Ednan discutiu uma experiência referente às literacias necessárias para a identificação de notícias falsas (fake news) e sua importância no contexto contemporâneo. Maristella, por sua vez, trouxe à baila reflexões sobre como a pesquisa em hábitos midiáticos de adolescentes pode ser algo importante para o conhecimento do ecossistema comunicativo da escola, contribuindo para a inserção da experiência midiática como processos.

\section{AS PRODUÇÕES DOS ALUNOS}

Como podemos observar na Figura 2, diversos formatos surgiram espontaneamente a partir da liberdade de produção oferecida. É claro que a tradicional de resenha escrita, que encontra correspondência naquela comum às publicações científicas, não deixou de fazer parte do rol de produções dos alunos. Isso se deu, especialmente, devido ao fato de as aulas no nível de graduação ministradas no IEL/Unicamp terem um forte intercâmbio com a pós-graduação: todos os professores do departamento estão presentes em, pelo menos, um programa stricto sensu, além de contar com monitor aluno de pós-graduação.

Todavia, vale ressaltar que, à medida que o curso evoluía, as produções em áudio, em vídeo, ou em formato que não o de resenha acadêmica, foram se tornando mais comuns. Tal transformação parece ter sido resultado de um processo de experimentação laboratorial por parte dos alunos. Já que parte significativa deles atua como professores, as possibilidades de escolha abertas pela liberdade de produção midiática passaram a ser paulatinamente transferidas para sua prática. Assim, a disciplina que ministrávamos tornou-se um local possível para testagem das ações de ensino e aprendizagem oferecidas por textualidades não tão comuns tanto no curso de letras, como no ensino de português para falantes nativos.

Um dos formatos que foram feitos pelos alunos foi o Vlog (ver Figura 2), que era sempre narrado em primeira pessoa, em plano único e com seus autores posicionados em frente à objetiva, como em vídeos de influenciadores digitais. Esse tipo de comunicação possui formato de depoimento, muitas vezes casual se comparado com o tradicional texto acadêmico outrora exigido. Houve uma produção em vídeo que trouxe uma entrevista ficcional, na qual os autores dos textos seriam entrevistados. 
comunicação \& educação • Ano XXVI • número 1 • jan/jun 2021

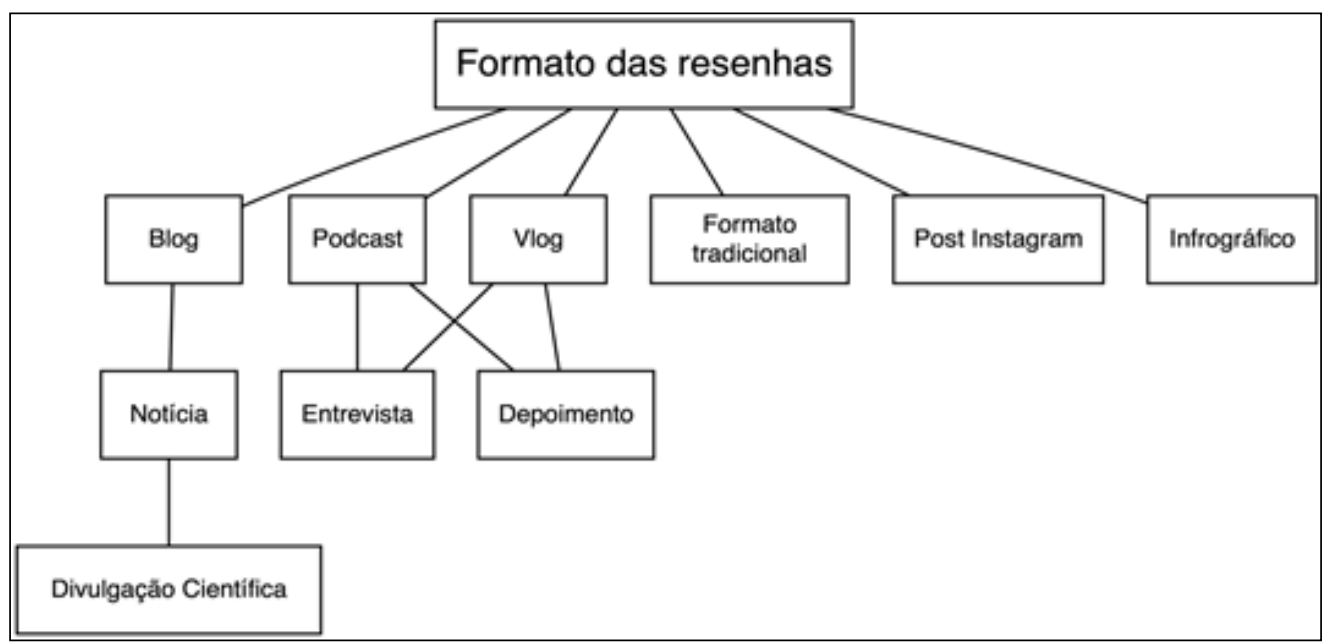

Figura 2: Natureza das produções no curso

Diferentemente do vídeo, as produções em áudio variavam entre três formatos preferenciais: entrevista, mesa redonda e depoimento. $\mathrm{Na}$ primeira, de caráter ficcional, os alunos encarnavam seus papéis de forma a refletir criticamente sobre um ou mais textos lidos, ao passo que, no segundo, tal reflexão era realizada de forma coletiva. No terceiro, as mesas redondas, as marcas de edição do áudio deixavam claro que os alunos estavam em localidades diferentes, gravando sua contribuição a partir de prévia roteirização. Já na última, o podcast era gravado por apenas um participante, apesar dos créditos informarem que mais participantes - necessariamente alunos do curso - estavam ligados às funções específicas da produção.

Além desses gêneros, ainda houve casos em que alguns alunos trouxeram produções no formato de um blog de notícias. Nesses blogs a reflexão se dava não apenas de forma narrativa, mas também buscavam relacionar os conteúdos lidos com outros disponíveis pela internet. A Figura 3 traz um exemplo dessa reflexão, no qual uma aluna utilizou os vídeos analisados por um dos artigos lidos em sala e realizou uma resenha crítica, replicando o estudo e traduzindo-o em uma linguagem menos acadêmica, como um site de divulgação científica. Ao mesmo tempo, essa aluna também reflete a importância que processos educomunicacionais e de comunicação para os meios poderiam contribuir para a formação de seus alunos em nível médio e fundamental. 


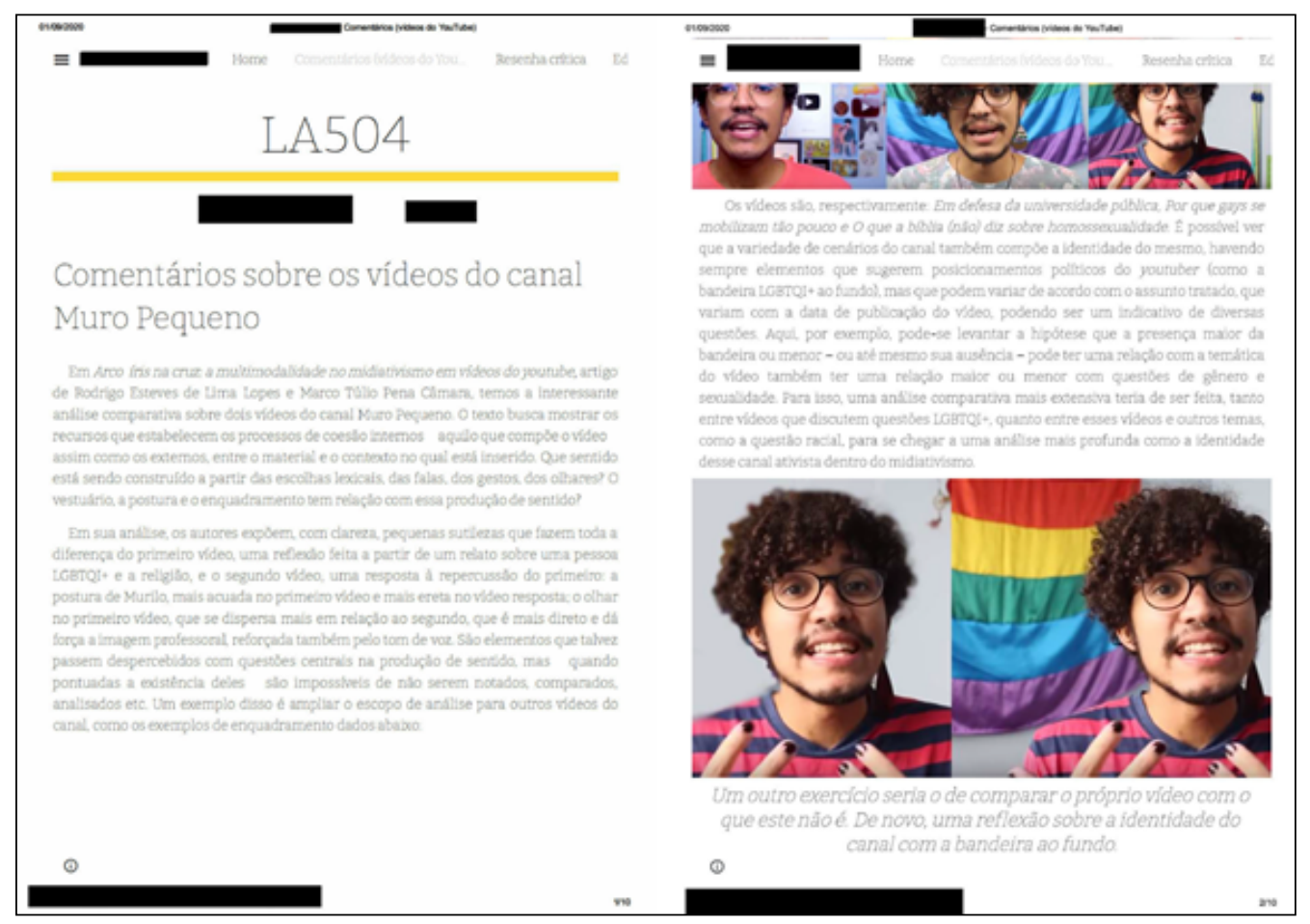

Figura 3: Exemplo de notícia de divulgação científica

Outros formatos apresentados pelos alunos durante o curso são o infográfico (ver Figura 4) e a postagem para stories do Instagram (Figura 5). No caso do primeiro formato, a aluna realizou uma sistematização de três textos para leitura de forma comparativa e sintética. A iniciativa, apesar de não se repetir, foi impactante nos demais alunos do curso, que declararam utilizar o material para compreensão dos textos. Do ponto de vista da análise de linguagem, tal formato levou a mobilização de uma importante capacidade tradutora, uma vez que houve a necessidade de transposição dos textos da linguagem acadêmica para a linguagem casual, e de síntese, uma vez que o texto produzido no infográfico traz apenas alguns dos elementos principais dos textos.

Essas mesmas capacidades tiveram de ser mobilizadas na produção da postagem para o stories do Instagram. Composto por 10 imagens contendo as temáticas principais de um dos textos, a aluna-autora se aproveitou da própria estrutura do texto como forma de articulação de sua produção. Algo que chamou a atenção foi a inserção de exemplos do contexto atual vivenciado pelos alunos em sala de aula. Tal inserção traz um tom de cor diferente, marcando semioticamente o discurso da aluna. 
comunicação \& educação • Ano XXVI • número 1 • jan/jun 2021

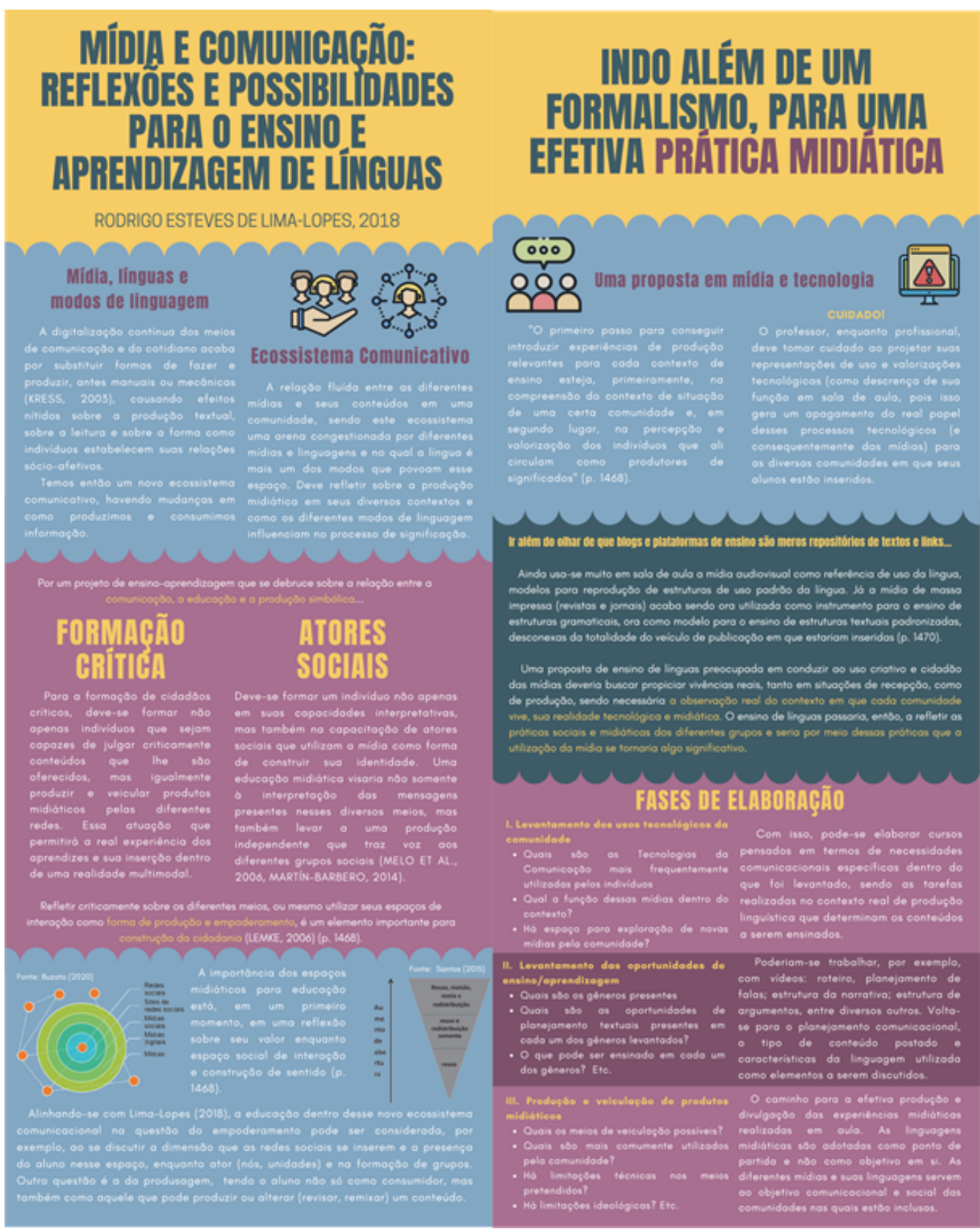

Figura 4: Infográfico
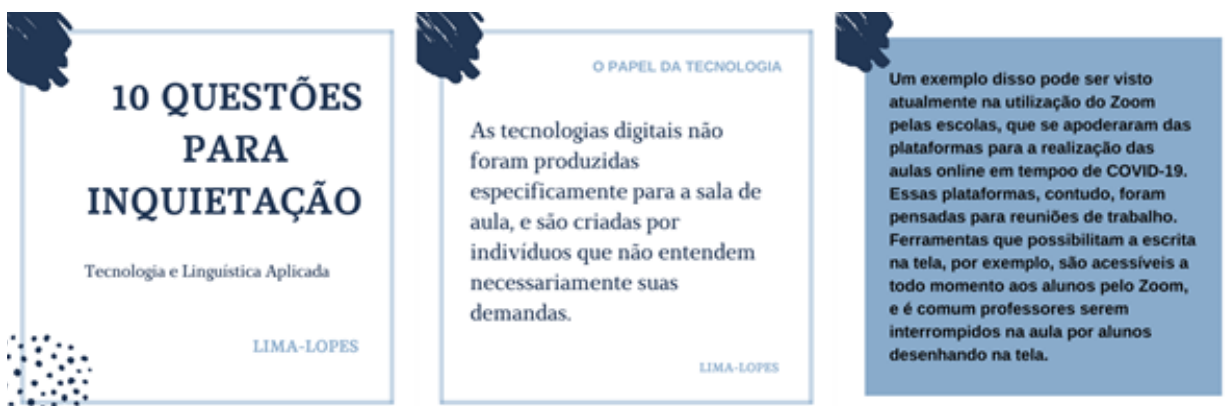

Figura 5: Post para o Instagram 


\section{CONSIDERAÇÕES FINAIS}

Este trabalho teve por objetivo refletir sobre as adaptações e transformações sofridas pela disciplina Linguagem e Tecnologias, oferecida no curso de Letras da Universidade Estadual de Campinas, por ocasião das transformações sociais e pedagógicas impostas pelo contexto da pandemia de Covid-19, em 2020.

De maneira geral, gostaríamos de avaliar o processo como positivo, apesar de a questão do isolamento ter se imposto como um elemento negativo em termos acadêmicos e pessoais em boa parte dos alunos do curso. A estratégia adotada de considerar os alunos como co-produtores de conhecimento, trazendo suas experiências e possibilitando que se expressassem por meio de diversos formatos textuais, todos ligados diretamente a práticas comunicacionais contemporâneas permitiu a criação de um forte senso de comunidade entre alunos, monitores e professor, levando a uma constante atividade de interação e aprendizado coletivo.

Todavia, cabe ressaltar que essas adaptações podem ter deixado algumas lacunas que, certamente, serão preenchidas em novas edições da disciplina. Entre elas, está a necessidade de maior discussão dos formatos midiáticos propostos, especialmente como eles podem ser utilizados pelo professor em formação em suas futuras aulas de língua materna. Apesar de haver relatos de algumas experiências $^{28}$, é necessário fazer mais estudos e sistematizações para promover a valorização dos processos comunicacionais no ensino de língua no Brasil.

\section{REFERÊNCIAS BIBLIOGRÁFICAS}

AMIEL, Tel. Educação aberta: configurando ambientes, práticas e recursos educacionais. In: SANTANA, Bianca; ROSSINI, Carolina; PRETTO, Nelson De Luca (org.). Recursos educacionais abertos: práticas colaborativas políticas públicas. Salvador: Edufba, 2012.

ASSIS, Leandro Marlon Barbosa; FARBIARZ, Alexandre. Conectar ou desconectar. Comunicação \& Educação, São Paulo, v. 23, n. 2, p. 21-33, 2018. BRIDLE, James. A nova idade das trevas: a tecnologia e o fim do futuro. São Paulo: Todavia, 2019.

BUCKINGHAM, David. A evolução da educação midiática no Reino Unido: algumas lições da história. Comunicação \& Educação, São Paulo, v. 21, n. 1, p. 73-84, 2016.

BUCKINGHAM, David. Media education: literacy, learning, and contemporary culture. Cambridge: Polity Press, 2003.

BUCKINGHAM, David. Precisamos realmente de educação para os meios?. Comunicação \& Educação, São Paulo, v. 17, n. 2, p. 41-60, 2012.

BUZATO, Marcelo El Khouri. Data sotrytelling e a datificação de tudo: um gênero bastardo de mãe narrativa e pai banco de dados. In: LIMA-LOPES,

28. LIMA-LOPES, Rodrigo Esteves de. Multimodalidade, ensino de línguas e formação de professores: uma experiência em educação para os meios. Travessias Interativas, São Cristóvão, v. 16, n. 2, p. 29-48, 2018. 
comunicação \& educação • Ano XXVI • número 1 • jan/jun 2021

Rodrigo Esteves de; BUZATO, Marcelo El Khouri (org.). Gênero reloading. Campinas: Pontes, 2018. p. 95-124.

CHOMSKY, Noam. Aspects of the Theory of Syntax. Cambridge/Mass: M.I.T. Press, 1969.

CITELLI, Adilson. Comunicação e educação: a linguagem em movimento. São Paulo: Editora Senac, 1999.

CITELLI, Adilson; SOARES, Ismar de Oliveira; LOPES, Maria Immacolata Vassallo de. Educomunicação: referências para uma construção metodológica. Comunicação \& Educação, São Paulo, v. 24, n. 2, p. 12-25, 2019.

COSTA, Maria Cristina Castilho; ROMANINI, Vinícius. A educomunicação na batalha contra as fake news. Comunicação \& Educação, São Paulo, v. 24, n. 2, p. 66-77, 2019.

FLUSSER, Vilém. Língua e realidade. São Paulo: Annablume, 2007.

FLUSSER, Vilém. O mundo codificado. São Paulo: Cosac Naif, 2007.

FRAU-MEIGS, Divina. Transletramento: operar a transição digital e o domínio das culturas da informação. Comunicação \& Educação, São Paulo, v. 19, n. 2, p. 61-73, 2014.

FREIRE, Paulo. Extensão ou Comunicação?. São Paulo: Paz \& Terra, 2006.

GABARDO, Maristella. Derrubando os muros: por que a escola brasileira deveria conhecer os usos da mídia feitos pelos adolescentes?. In: LIMALOPES, Rodrigo Esteves de; GABARDO, Maristella (org.). Horizontes em tecnologia, ensino e sociedade: diálogos interdisciplinares em linguística aplicada. Curitiba: Editora do IFPR, 2021. p. 35-54.

HALLIDAY, Michael. Language as social semiotic: the social interpretation of language and meaning. London: University Park Press, 1978.

KRESS, Gunther. Against Arbitrariness: the social production of the sign as a foundational issue in critical discourse analysis. Discourse \& Society, Thousand Oaks, v. 4, n. 2, p. 169-191, 1993.

LASSALVIA, Catia Silene Camara. Aprendizagem ao longo da vida: entre a metonímia neoliberal e as trajetórias. In: LIMA-LOPES, Rodrigo Esteves de; GABARDO, Maristella (org.). Horizontes em tecnologia, ensino e sociedade: diálogos interdisciplinares em linguística aplicada. Curitiba: Editora do IFPR, 2021, p. 55-68.

LÉVY, Pierre. Os três tempos do espírito: a oralidade primária, a escrita e a informática. In: LÉVY, Pierre. As tecnologias da inteligência. São Paulo: Editora 34, 1997. p. 46-81.

LIMA-LOPES, Rodrigo Esteves de. Apontamentos sobre mídias digitais: qual caminho para o Gênero 2.0? In: LIMA-LOPES, R. E. de; BUZATO, Marcelo El Khouri (org.). Gênero Reloading. Campinas: Pontes, 2018. p. 14-41. 
LIMA-LOPES, Rodrigo Esteves de. Mídia e comunicação: reflexões e possibilidades para o ensino e aprendizagem de línguas. In: CONGRESSO IBERCOM 2017: COMUNICAÇÃO, DIVERSIDADE E TOLERÂNCIA, 15., 2018, São Paulo. Anais [...]. São Paulo: ECA-USP, 2018. p. 1463-1480.

LIMA-LOPES, Rodrigo Esteves de. Multimodalidade, ensino de línguas e formação de professores: uma experiência em educação para os meios. Travessias Interativas, São Cristóvão, v. 16, n. 2, p. 29-48, 2018.

LIMA-LOPES, Rodrigo Esteves de.; CÂMARA, Marco Túlio. Arco-íris na cruz: a multimodalidade no midiativismo em vídeos no YouTube. Policromias, Rio de Janeiro, v. 4, n. 2, p. 97-121, 2019.

LYONS, John. Semantics: volume 1. Cambridge: Cambridge University Press, 1977.

MARTINEC, Radan. Nascent and mature uses of a semiotic system: the case of image-text relations. Visual Communication, Thousand Oaks, v. 12, n. 2, p. 147-172, 2013.

MORAN, José. Mudando a educação com metodologias ativas. In: SOUZA, Carlos Alberto de; MORALES, Ofelia Elisa Torres (org.). Convergências midiáticas, educação e cidadania: aproximações jovens. Ponta Grossa: [S. n.], 2015.

O'HALLORAN, Kay L. Visual semiosis in film. In: O'HALLORAN, Kay L. (org.). Multimodal discourse analysis: systemic-functional perspectives. London: Continuum, 2004.

SCOLARI, Carlos Alberto. Ecología de los medios: entornos, evoluciones e interpretaciones. Barcelona: Gedisa, 2015.

SOARES, Magda. Novas práticas de leitura e escrita: letramento na cibercultura. Educação \& Sociedade, Campinas, v. 23, n. 81, p. 143-160, 2002.

VALENTE, José Armando. Blended learning e as mudanças no ensino superior: a proposta da sala de aula invertida. Educar em Revista, Curitiba, n. spe4, p. 79-97, 2014. 